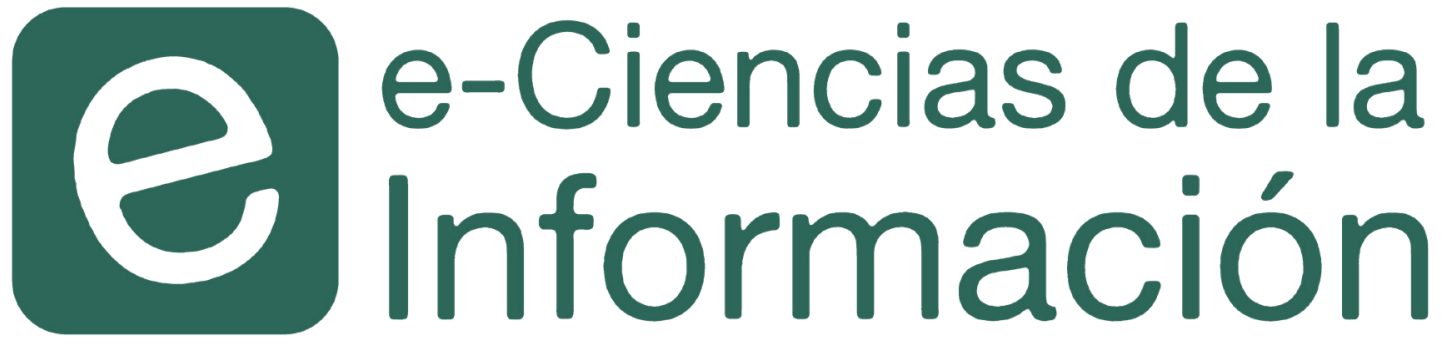

\title{
O incentivo do gosto pela leitura em bibliotecas públicas: um subsídio para a biblioteca nacional de Angola
}

\section{Nsenga Luísa Onde} Santos Garcia Simão

\section{Recibido:03/05/2019 | Corregido: 23/08/2019 | Aceptado:25/09/2019 DOI: $10.15517 /$ eci.v10i1.39775}

e-Ciencias de la Información, volumen 10, número 1, Ene- Jun 2020

ISSN: 1649-4142

\section{(ㄷ)(1)(2)(2)}

\section{¿Cómo citar este artículo?}

Luísa Onde, N. y Garcia Simão, S. (2020). O incentivo do gosto pela leitura em bibliotecas públicas: um subsídio para a biblioteca nacional de Angola. e-Ciencias de la Información, 10(1). DOI: 10.15517/eci. 


\title{
O incentivo do gosto pela leitura em bibliotecas públicas: um subsídio para a biblioteca nacional de Angola
}

\author{
The incentive of the taste for reading in public libraries: \\ a subsidy for the national library of Angola
}

\section{El incentivo del gusto por la lectura en bibliotecas públi- cas: un subsidio para la biblioteca nacional de Angola}

Nsenga Luísa Onde (1) ${ }^{1}$

Santos Garcia Simão (1) ${ }^{2}$

\section{RESUMO}

A pesquisa consiste na análise sobre o comportamento dos usuários face ao gosto pela leitura. Hoje, a leitura é um activo de grande importância para adquirir o conhecimento por ser o principal recurso utilizado na formação de um ser intelectual, sendo assim, muito mais valioso e poderoso que qualquer outro meio de aquisição do conhecimento. O presente estudo, apresenta uma revisão literária sobre as principais características da leitura na formação de um leitor crítico. Diante deste cenário, o objectivo da pesquisa é de apresentar uma estratégia como resultado sobre o processo de promoção de leitura nas bibliotecas públicas em Angola. Trata-se de um estudo de caso, onde foram utilizados em abordagens qualitativa-quantitativa e como técnicas, foram empregues á análise documental e bibliográficas, a observação, o inquérito por questionário e entrevistas. O resultado demonstra a necessidade de um desenho de estratégias metodológica que contribua no incentivo do gosto pela leitura dos usuários das bibliotecas públicas, caso específico da Biblioteca Nacional de Angola.

Palavras-chaves: Promoção de Leitura. Incentivo da Leitura. Estratégia de Leitura.

\section{ABSTRACT}

The research consists of the analysis about the behavior of the users against the taste for reading. Today, reading is a very important asset for acquiring knowledge because it is the main resource used in the formation of an intellectual being, thus being much more valuable and powerful than any other means of acquiring knowledge. The present study presents a literary review on the main characteristics of reading in the formation of a critical reader. In view of this scenario, the objective of the research is to present a strategy as a result of the reading promotion process in public libraries in

\footnotetext{
'Instituto Superior de Ciências da Comunicação, ANGOLA. E-mail:. luinsenga31@gmail.com

${ }^{2}$ Instituto Superior de Ciências da Comunicação, ANGOLA. E-mail: mestrearquivosflul@outlook.pt ORCID: 
Angola. It is a case study, where they were used in qualitative-quantitative approaches and as techniques, were used for documentary and bibliographic analysis, observation, questionnaire survey and interviews. The result demonstrates the need for a methodological strategy design that contributes to the incentive of reading libraries users, in the specific case of the National Library of Angola.

Key Words: Promotion of Reading. Reading Incentive. Reading Strategy.

\section{RESUMEN}

La investigación consiste en el análisis sobre el comportamiento de los usuarios frente al gusto por la lectura. Hoy, la lectura es un activo de gran importancia para adquirir el conocimiento por ser el principal recurso utilizado en la formación de un ser intelectual, siendo así, mucho más valioso y poderoso que cualquier otro medio de adquisición del conocimiento. El presente estudio, presenta una revisión literaria sobre las principales características de la lectura en la formación de un lector crítico. Ante este escenario, el objetivo de la investigación es presentar una estrategia como resultado sobre el proceso de promoción de lectura en las bibliotecas públicas en Angola. Se trata de un estudio de caso, donde se utilizaron en enfoques cualitativo-cuantitativos y como técnicas, se utilizaron para el análisis documental y bibliográfico, la observación, la encuesta por cuestionario y entrevistas. El resultado demuestra la necesidad de un diseño de estrategias metodológicas que contribuya al incentivo del gusto por la lectura de los usuarios de las bibliotecas públicas, caso específico de la Biblioteca Nacional de Angola.

Palabras clave: Promoción de Lectura. Incentivo de la lectura. Estrategias de lectura.

\section{INTRODUÇÃO}

Desde a Antiguidade até aos dias de hoje, a leitura espelha os costumes, a cultura, e os valores dos cidadãos de cada época e de cada espaço geográfico em uma expressão do homem como criador e autor da obra escrita. A biblioteca é um espaço de grande potencial para o desenvolvimento de actividades relacionadas à leitura, o que contribui para despertar a criatividade e o senso crítico do usuário sendo, portanto, um instrumento fundamental no processo de aprendizagem. Com isso, a leitura é considerada um processo de elaboração e verificação de hipóteses que levam à construção de uma interpretação, é neste processo de leitura e transformação da informação em conhecimento, que a biblioteca surge como espaço rico em recursos e possibilidades.

É nos livros que temos a chance de entrar em contacto com o desconhecido conhecer outras épocas e outros lugares e, com eles desenmvolver a mente. Por isso, incentivar a formação de leitores é não apenas fundamental no mundo globalizado em que vivemos. A Biblioteca Pública aqui tratada consolidou-se antes da independência de Angola, isto é em 1969. (Decretolei, $\left.n^{\circ} 49.448,1969\right)$. 
A partir deste momento, foram evidenciados esforços para o incentivo e o gosto pela leitura. A Biblioteca Nacional tem como objectivo satisfazer as necessidades no âmbito da Educação e da Cultura, por meio de diversos serviços que permite ao usuário encontrar respostas para as suas indagações, e dessa forma satisfazer suas necessidades informacionais.

Na óptica da cultura informacional, as bibliotecas públicas devem destacar-se como espaços de conquista do direito à informação, à leitura e à cidadania elementos cada vez mais indispensáveis na sociedade, diante das exigências do mundo contemporâneo, enfatiza Cavalcante (2006). A leitura é primordial para qualquer indivíduo é com está ferramenta que conseguimos alcançar ou obter novos conhecimentos e engrandecermos as nossas capacidades educacionais, isto levou a desenhar estratégia metodológica para o melhorar a contribuição da Biblioteca Nacional para o incentivo do gosto pela leitura na Biblioteca. Este tema tem como finalidade ajudar a Biblioteca nas práticas usadas para o incentivo do gosto pela leitura e mostrar as pessoas o quão importante é a leitura para o engrandecimento do seu intelecto. Quanto as finalidades das Bibliotecas Públicas, a Rede Nacional de Bibliotecas Públicas de Angola salienta que,

As Bibliotecas Públicas visam o acesso aos recursos informativos e à leitura, bem como à satisfação das necessidades informativas das comunidades, comfins educativos, deinvestigação, delazere culturais. (...) são estabelecimentos públicos, de âmbito local, tutelados pelo Estado, sem fins lucrativos, de carácter científico, cultural e educativo, prestando à toda comunidade um serviço público de leitura e acesso à informação. (...) Promover o acesso à leitura, consulta e estudos, com recurso a diferentes tipos de documentos nos mais variados suportes. (Decreto Presidencial n. 270, 2011).

Só com uma boa leitura conseguiremos entender o que estamos a ler e ter a certeza de que a informação que temos é o que precisamos para satisfazer as nossas necessidades informacionais e para isso, não basta lermos o título, mas sim o documento todo.

A pesquisa Justifica-se pelo facto de não existirem no país estudos virados ao incentivo pela leitura nas bibliotecas. Visto que a leitura é um ativo de muita importância o desenvolvimento de um país, e Angola sendo um país em crescimento, necessita de pessoas qualificadas capazes de responder os desafios globais. Isto só será possível, caso haja por parte do cidadão angolano o gosto pela leitura. Isto levou-nos a desenhar estratégia metodológica para o melhorar o gosto pela leitura nas Bibliotecas Públicas de Angola, caso de estudo na Biblioteca Nacional de Angola.

Outrossim, verifica-se a orientação para as bibliotecas públicas angolanas, no sentido de facilitar o acesso e a democratização dos serviços, aliando-os as novas tecnologias. Por outra, como parte integrante do cenário da Sociedade da Informação, a Biblioteca Pública precisa apropriar-se das Tecnologias de Informação e Comunicação, a fim de permitir uma disseminação eficaz da informação e o actuar de maneira eficiente e consciente.

Apresenta-se como problema científico o seguinte: Como Incentivar o gosto pela Leitura nos usuários da Biblioteca Nacional de Angola? Com isso, pretende-se mostrar aos usuários e público em geral a importância de uma Biblioteca assim como, os serviços e produtos oferecidos, estes, bem utilizadas, fazem com que os usuários percebam do valor que tem a leitura e 
os seus benefícios. Para minimizar-mos a problemática, elaboramos através de estrategias já conhecidas, uma metodologia para o incentivo do gosto pela leitura aos usuários da Biblioteca Nacional de Angola.

\section{REFERENCIAL TEÓRICO}

\subsection{As Bibliotecas Públicas: acesso e democratização}

As bibliotecas são instituições antigas, elas são mais remotas que o próprio livro. Desde a Antiguidade já existiam bibliotecas, mas até a Renascença estas eram tidas como sagradas, com acesso restrito aos monges e sacerdotes e se apresentavam imbuídas de uma aura de mistério, o que chamamos neste trabalho de "biblioteca do poder centralizado". A biblioteca pública tem um papel primordial no que se refere à democratização do acesso à informação, na medida em que recebe, sem distinção, qualquer pessoa independente de sua classe social, sexo, orientação sexual ou religião, tornando-se a mais democrática de todos os tipos de biblioteca.

Existem enúmeras dificuldades no exercício da conceituação das bibliotecas, "a dificuldade maior está exatamente em conceituar biblioteca pública" (Milanesi, 1986, p.95). Esta dificuldade surge devido a amplitude de seu atendimento, pelas diretrizes educativas do Manifesto da UNESCO, pela sua própria deficiência, sobretudo, pelas mudanças impostas pelos novos tempos, pela era da informação e conhecimento. Além do mais, o Manifesto da IFLA/UNESCO para as Bibliotecas Públicas, edição 2000, aborda que a Biblioteca Pública também deverá desempenhar o papel de preservação da memória local, guardando e disponibilizando a produção cultural da sua comunidade e região.

Uma biblioteca bem estruturada, dinamizada por profissionais especializados (bibliotecários) pode se tornar numa ferramenta poderosa para a formação de leitores, essencialmente quando realizados projectos que visam desenvolver o hábito de as frequentar. Historicamente, os tipos de bibliotecas foram aperfeiçoando-se, modificando e adaptando-se às novas realidades mundiais. A título de exemplo, sem sair de casa, as pessoas podem ter acesso ao acervo bibliográfico através do uso da internet, ou seja, a biblioteca também se adaptou ao mundo globalizado. Sobre a modernização dos serviços nas bibliotecas públicas de Angola, os artigos. ${ }^{\circ} 9$ e 10 do diploma que cria a Rede Nacional de Bibliotecas Públicas de Angola, descrevem o seguinte,

Proporcionar o acesso às modernas tecnologias de informação e da comunicação e ao conhecimento das inovações científicas. (...) Devem prestar serviços complementares adequados aos seus utentes e às novas tecnologias, bem como serviços específicos destinados a utilizadores com necessidades especiais. (Decreto Presidencial n. ${ }^{\circ}$ 270, 2011).

O processo da democratização das bibliotecas públicas, não é recente. Já na Idade Média, com o surgimento das primeiras universidades, a biblioteca pública foi acentuando o seu carácter democrático. Nesse período sustentase a ideia de que,

O conhecimento preso ao livro torna-se de pouco valor havendo a necessidade de disseminá-lo para gerar o enriquecimento intelectual 
dos indivíduos e da colectividade, onde o foco deixa de ser o livro e se transfere para o leitor. (Jacob, 2000 citado por Santos, 2014, p.56).

As Bibliotecas da época, tinham como principal objectivo, coleccionar elevado número de obras para a consulta privada. Com o passar dos anos, o objectivo deixou de ser o acervo bibliográfico e o usuário tornou-se o epicentro, sendo ele o principal interessado no acervo que as mesmas possuíam. Verifica-se claramente a ideia de bibliotecas de proximidades, onde o foco é a satisfação das necessidades de informação dos usuários. Desse modo "[...] a participação construtiva e o desenvolvimento da democracia dependem tanto de uma educação satisfatória como de um acesso livre e sem limites ao conhecimento, ao pensamento, à cultura e à informação [...]" (Manifesto da IFLA UNESCO para Bibliotecas Públicas [IFLA],1994, p.1).

A definição demonstra que, a Biblioteca Pública assume muitos papéis perante a actual sociedade, sendo um espaço gratuito para a democratização da informação, que deve prover informação da melhor forma possível, buscando sempre atender as necessidades do usuário. Entende-se que "a criação de Bibliotecas Públicas é uma das actividades necessárias para o desenvolvimento cultural de um país" (Freitas e Silva, 2014, p.124).

Essas bibliotecas, provavelmente, não irão resolver os problemas como o analfabetismo, por exemplo, mas poderão disseminar na população o hábito de ler. Feito isso, de forma bem orientada, a população será mais esclarecida e mais bem orientada, Andrade (1957) citado por Freitas e Silva (2014).

Os elementos importantes ligados às bibliotecas são,

Os serviços e o acervo. Os serviços da biblioteca devem ser fisicamente acessíveis a todos os membros da comunidade e, para isto, requer que a biblioteca esteja bem localizada, com instalações correctas para a leitura e estudo, assim como com tecnologias adequadas e horário de funcionamento conveniente aos usuários. O acervo da biblioteca deve refletir as tendências actuais e a evolução da sociedade, deve reflectir a memória das conquistas e imaginação da humanidade. (IFLA, 2000, pp. 2-3).

Assim, tanto as coleções quanto os serviços, não podem ser objectos de nenhuma forma de censura ideológica, política ou religiosa nem de pressões comercial.

\section{MÉTODOS E TÉCNICAS DE INVESTIGAÇÃO UTILIZADAS}

O método significa estratégias de produção de conhecimento científico, que sintetiza, analisa, compreende e, ainda, pode e deve gerar e validar teorias. O método é entendido como o "conjunto concertado de operações que são realizadas para atingir um ou mais objectivos, um corpo de princípios que presidem a toda investigação organizada, um conjunto de normas que permitem seleccionar e coordenar as técnicas" (Carmo e Ferreira 2008, p.18).

Mas, quanto a tipologia é um trabalho de natureza mista (quantitativaqualitativa).

Assim, a pesquisa mista é o procedimento de coleta e análise de informação, onde se pode combinar duas pesquisas que são, no contexto deste trabalho, por um lado, a Pesquisa Descritiva e a Pesquisa Bibliográfica. Pesquisa Descritiva 
aquela que procura descrever um fenómeno sem que o investigador interfira nele e, por outro, a Pesquisa Bibliográfica, aquela que se baseia em bibliografias já existentes. E foram empregues os métodos de nível teórico e empírico.

Métodos de nivel teórico: Análise Documental

A análise documental vale-se de documentos originais, que ainda não receberam tratamento analítico. Trata-se de uma técnica de coleta de dados que elimina, ao menos em parte, a eventualidade de qualquer influência, presença ou intervenção do pesquisador, do conjunto das interacções, acontecimentos ou comportamentos pesquisados, anulando a possibilidade de reação do sujeito à operação de medida, (Silva, Almeida \& Guindani, 2009). Permitiu que se fizesse uma análise exaustiva de todos os documentos encontrados e fornecidos para a realização desta investigação, assim como as referências bibliográficas, selecionadas para o marco teórico e conceptual do trabalho.

\section{FUNCIONALIDADE E OBJECTIVIDADE DAS BIBLIOTECAS PÚBLICAS}

\subsection{Biblioteca pública: função e objectivo}

As bibliotecas públicas desempenham muitas funções, a fim de atenderem os objectivos pelas quais foram criadas, uma delas, é o de atender as necessidades informacionais ao cidadão e a democratização senário bibliográfico. Durante o percurso histórico,

As bibliotecas públicas, de uma forma ou de outra, tiveram como funções básicas a coleta, a conservação, a organização e a difusão de informações, e têm buscado, através da difusão do conhecimento, a produção de um bem social. (Mueller, 1984 citado por Bernardino e Suaiden, 2011, p.39).

A função social da biblioteca pública necessita de um maior empenho e de constantes avaliações.

Dando ênfase ao entendimento do autor anterior, pode-se mesmo dizer que a função da Biblioteca Pública é justamente a de promover o livre acesso à informação, buscando uma integração entre a sociedade e essas informações por ela disponibilizadas. Seu papel não é apenas o de disponibilizar a informação, mas sim o de promover serviços que incentivem o uso dessas informações e que desperte em cada um o prazer da leitura.

Outra função consiste em conhecer os seus usuários. Outrossim "a biblioteca pública perecerá se não se retroalimentar com seu público" (Feitosa, 1998, p.34). Isto significa que é preciso estratégias consistentes no sentido de trazer a população e/ou o usuária para dentro da biblioteca. Assim, para que isto aconteça, as Bibliotecas Públicas devem preocupar-se com as reais necessidades informacionais de cada um dos usuários, por forma a satisfazêlos melhor.

É função primordial dos bibliotecários priorizarem o desenvolvimento de suas funções de acordo com a realidade local e identificar novas funções dentro da comunidade. Outra função é a de criar e manter projectos culturais que visam atender à demanda da comunidade usuária, no que diz respeito à disseminação da leitura e da cultura, é responsabilidade da biblioteca pública. 
Para Pereira (2015) a biblioteca pública representa um elo entre a necessidade de informação dos membros da comunidade e o recurso informacional que nela se encontra organizado e a disposição dos usuários.

Quanto ao que as bibliotecas possam oferecer, Fonseca (2007) citado por Borges (2016), além da prestação de serviços informacionais, culturais e de entretenimento, as Bibliotecas Públicas viabilizam o acesso à leitura e a formação de leitores. Por seu turno, Gomes (2016), os objetivos da Biblioteca Pública, como instituição democrática de educação, informação, cultura e lazer são:

a) A nível da educação

Promover e fornecer meios para o auto desenvolvimento do indivíduo, seja qual for o seu nível de educação, eliminando a barreira entre o indivíduo e os conhecimentos;

b) A nível da informação

Fornecer ao indivíduo/grupo informações certas, com rapidez e em profundidade, particularmente sobre assuntos de interesse corrente;

c) A nível da cultura

Ser um dos principais centros da vida cultural e promover uma maior fruição, prazer e apreciação de todas as artes;

d) A nível do lazer

Participar no encorajamento à utilização positiva do lazer e facultar meios de mudança e descontração.

Por outro lado, o Manifesto da INFLA (1994) cita como principal objetivo da biblioteca pública o de fornecer recursos e serviços em diversos suportes, de modo a chegar ao encontro das necessidades individuais ou coletivas, no domínio da educação, informação e desenvolvimento pessoal e também de recreação e lazer. Isto vem a demonstrar que, a biblioteca pública, desempenha um papel importante no desenvolvimento e manutenção de uma sociedade democrática, ao dar aos indivíduos acesso a um vasto campo de conhecimento, ideias e opiniões.

O Manifesto assume como objectivos e funções das Bibliotecas Públicas:

1. Porta de entrada para o conhecimento;

2. Força viva para a educação, cultura e informação;

3. Agente essencial para a promoção da paz e do bem-estar espiritual da humanidade.

Sendo a Biblioteca Nacional uma biblioteca pública, ela asssume um papel importante na sociedade angolana, como modificador e facilitador da compreensão dos factos e acopn tecoimentos sociais. Ela é o pulmão do indicador da qualidade do ensino e investigação de uma Universidade, país ou nação.

\subsection{A leitura em bibliotecas públicas}

A leitura é um dos vetores das bibliotecas públicas, pois, elas inspiram confiança, motivação e o desejo da mundança de comportamento. Hoje, as bibliotecas públicas devem e são obrigados a proporcionar um espírito saudável para a leitura, isto é, um espaço onde o leitor entra e fica por lá até a sua morte. 
A leitura, os livros e a biblioteca permitem fazer frente às exigências do futuro, com a necessidade de lidar com a informação e saber usá-la para desenvolver o espirito crítico. É através do acto de ler que o homem interage com outros homens por meio da palavra escrita. O leitor é um ser activo que dá sentido ao texto. A palavra escrita ganha significados a partir da acção do leitor sobre ela. (Silva, 2011).

Um dos actos mais urgentes é o de investir em material humano, com a formação de mediadores e bibliotecários capazes de semear o prazer à leitura por todo o país. Os mediadores são os instrumentos mais eficientes para fazer da leitura uma prática social mais difundida e aproveitada (Lima, 2008). O acto da leitura é importante nessa fase para transformar o aluno leitor passivo em leitor sujeito, pois, só através dessa acção, ele se tornará capaz de construir sua própria leitura e analisar sua visão de mundo.

Autores como Freitas e Silva (2014) afirmam que a biblioteca pública é de extrema importância para uma sociedade, por ser como que um agente do qual provém a informação, sendo assim, um meio de democratização da leitura e do conhecimento para um país.

Tendo como meta a democratização da informação para todos os níveis, a bibliotecas públicas tem que se preocupar com o hábito de leitura dos seus usuários, sendo que a leitura é a principal ferramenta que facilita o acesso à informação. Cabe as bibliotecas públicas criar actividades que despertem o gosto pela leitura aos seus usuários e estes possuírem capacidades de interpretação e dessa forma se tornarem em um leitor crítico ( Hillesheim e Fachin, 2003).

Na mesma linha de pessamento, Macedo e Siqueira (2000) citados por Carvalho (2011) afirmam que as bibliotecas públicas devem apoiar e participar de actividades e programas de alfabetização, ampliando as oportunidades de leitura aos indivíduos recém-alfabetizados dentro das especificidades da biblioteca, grupos com necessidades educativas especiais e as minorias sociais. Se necessário e se possível, enveredar esforços para implantar tais actividades, oferecendo até espaços físicos.

Contudo, pensar em leitura obriga às pessoas, desde logo, a pensar em alfabetização, pois, só na sociedade alfabetizada se pode fomentar uma relação estável com o livro e a leitura.

\subsubsection{Conceituando a Leitura}

Apresentar um conceito sobre leitura torna-se uma difícil questão porque ela se manifesta de diversas formas, por meio de imagens, sons, sentimentos e emoções e pela própria vivência do homem em seu quotidiano. Segundo Souza (2009, p. 15), a "leitura, iniciada com a história da humanidade pela decifração de imagens deixadas pelos primitivos, muitas vezes, ainda é vista somente como decodificação de signos linguísticos, mas sua importância tem sido evidenciada com o passar do tempo".

Vários são os conceitos apresentados acerca da leitura. Assim a "leitura é o ato ou efeito de ler, arte, hábito de ler; aquilo que se ler" (Tersariol, s.d, p. 266). O ato de ler,

Éumprocessoabrangenteecomplexo;éum processodecompreensão, 
de intelecção de mundo que envolve uma característica essencial e singular ao homem: a sua capacidade simbólica e de interação com o outro pela mediação de palavras. $O$ ato de ler não pode se caracterizar como uma atividade passiva. (Brandão e Micheletti, 2002 citados por Silva, 2011, p. 22).

Vê-se claramente, que é através da leitura que conseguimos interagir com o mundo, com a pessoa que escreve. Assim, entedemos que a leitura é o diálogo aberto entre o escritor, professor e o leitor/aluno. Quem lê pode tornar-se exemplo para a sociedade ou maldição, dependendo da pessoa que lê e do que leu.

Por outro lado, a leitura como um processo abrangente e democrático é, (...) Um processo no qual o leitor realiza um trabalho ativo de construção do significado do texto, a partir dos seus objetivos, do seu conhecimento sobre o assunto, sobre o autor, de tudo o que sabe sobre a língua: características do gênero, do portador, do sistema de escrita, etc. (Parâmetros Curriculares Nacionais, 2001 citado por Silva, 2011,p.23).

Como um ato bilateral entre o sujeito e a sociedade, a "leitura é um ato social, entre dois sujeitos - leitor e autor - que interagem entre si, obedecendo a objetivos e necessidades socialmente determinados" (Kleiman, 1997, p.10).

Kleiman (1997) citado por Silva (2015) pontua que a leitura é um ato individual de construção de significados num contexto que se configura mediante a interação entre leitor e autor e, portanto, será diferente para cada leitor dependendo de seus interesses, conhecimento e objetivos do momento.

Concluindo, podemos dizer que a leitura é um fenómeno bilateral, onde os principais envolventes são: o escritor e o leitor.

\subsubsection{0 processo de promoção de leitura nas bibliotecas públicas}

A promoção de leitura é uma área que se encontra em crescimento, abrangendo diversos sectores, maioritariamente na educação e na cultura, estando-se a alargar para os campos da saúde e ciências sociais. Na educação, além de ser autónoma, é complementada pelo sistema de ensino, com o trabalho desenvolvido pelas bibliotecas escolares e também nas actividades desenvolvidas dentro da sala de aula.

Quanto a questão da prática da leitura, é de refetrir que,

(...) abrangem variados níveis mediante a população-alvo, desde o desenvolvimento de competências de compreensão da escrita (alfabetização), até à elevação dos conhecimentos tanto em quantidade como em qualidade, tendo em vista aumentar o gosto pela leitura, e que esse mesmo gosto seja transmitido aos seguintes, reduzindo com isso a médio/longo prazo os níveis de iliteracia gerais. (Gomes, 2016, p.32)

Ademais, Gomes (2016) afirma que, a promoção da leitura é uma prática a qual se pode chamar animação da leitura. A animação existe no momento em que realizamos uma actividade com determinado tema e fim onde, um dos principais objectivos é animar o tempo em que se realiza a dinâmica. 
Na promoção da leitura, aborda-se a animação da biblioteca pois parece o local ideal para o colocar em prática. Atribui-se assim, ao espaço uma importância elevada, a casa da leitura e do conhecimento, e parece por excelência o melhor local, Basílio (2016).

Pode-se dizer que, seja nas escolas, nas bibliotecas, em casa, individualmente ou em grupo, deve-se fomentar o hábito e gosto pela leitura, criando actividades e estratégias que a promovam. Pode-se fazê-lo enquanto pais, professores, educadores ou animadores. $O$ ideal é que haja uma continuidade da promoção da leitura, permitindo que ela esteja presente de uma forma natural em casa, nas instituições de ensino e nas bibliotecas públicas.

Gomes (2016) demonstra vários problemas, normalmente apontados como causas para a falta do hábito e interesse pela leitura e entre eles são:

1. Um ambiente familiar complicado;

2. A falta de apoio e incentivo por parte dos pais, familiares, educadores e docentes;

3. A ocupação com vários tipos de tarefas que não desenvolvam a leitura e o intelecto;

4. Algum mau momento vivenciado, mal resolvido, que leva à falta de interesse;

5. A carência de apoio e de esclarecimento; entre outros.

A prática do gosto pela leitura, deve ser um exercício cultivado na infância, cujo palco deve ser obrigatoriamente em casa. Isto permitirá, que o indivíduo venha a usufruir os benefícios da leitura, agregado a formação do leitor, na sua formação pessoal e profissional, e na habilidade de se expressar tanto de forma oral como escrita e que perceba a informação como um produto natural de sua leitura.

\subsection{Procurando estratégias para a promoção da leitura}

Pretende-se nesta parte do trabalho, apresentar as principais estrategias acerca da promoção da leitura.

Nesta senda, Carvalho, Nobre, Gauer \& Salles (2015), consideran algumas estratégias que a biblioteca deve ou pode dispor como atractivo para grupos de crianças ou de estudantes, tais como:

1. Deixar a criança e/ou as pessoas explorar o livro, as suas formas, cores e texturas;

2. Contar historia e mostrar as ilustrações;

3. Ter espaços, condições e pessoal para receber grupos de escolas,

4. Dinamizar actividades ao ar livre ou dentro;

5. Proporcionar momentos de brincadeira e recreio;

6. Orientar as pessoas, alunos na escolha de um livro, na pesquisa de algo, na opção de requisição de livros.

Neste ponto de vista, Gomes (2016) estabelece dois perfis sociais, e, como tal, duas estratégias diferentes do ponto de vista da promoção da leitura.

a. Uma delas seria no aprimoramento da leitura, junto daqueles que são mais favoráveis - escolaridade mais elevada, mais jovens, mulheres, e quando activos nos profissionais técnicos e de enquadramento e empregados 
executantes.

b. A outra seria no sentido de aumentar em quantidade e qualidade a leitura naqueles menos favoráveis - escolaridade mais baixa, mais idosos, homens, não activos (reformados/as, domésticos/as) e quando activos, nos operários.

Estas diferenças existentes e verificadas podem ajudar a definir estratégias de promoção de leitura dentro das várias classes e famílias. Identificando mais facilmente dentro de uma família se se usar os progenitores para orientar os descendentes ou o inverso, (Neves, Lima e Borges 2007 citados por Gomes, 2016). Outras estratégias tidas em consideração foram: Estratégias da leitura na escola de Arana, Albano, \& Ferreira (2013), a Dinamização Pedagógica de Cichoski (1999), a Narrativa transmídia como estratégia de incentivo à leitura de Elisa Cristina Delfini Corrêa (2014) e a Estratégias de incentivo à leitura nas escolas estaduais do estado de Minas Gerais de Secretaria de Estado de Educação de Minas Gerais (2017).

A elaboração de uma estratégia para incentivar o gosto pela leitura é uma aposta do investigador para melhorar o processo de promoção de leitura na Biblioteca Nacional de Angola. A metodologia usada para a elaboração da referida estratégia, baseou-se nos trabalhos de vários autores que abordam sobre o mesmo assunto. Desta feita, teve-se em consideração autores como Damasceno que define, a Narrativa transmídia como uma Estratégia de promoção de leitura e também na Estratégia usada nas escolas estaduais do estado de Minas Gerais, que se adaptou ao contexto da Biblioteca Nacional.

\section{ESTRATÉGIAS PARA A PROMOÇÃO DA LEITURA}

\subsection{Estratégia escolhida para a promoção de leitura para as bibliotecas públicas}

A partir da utilização dos métodos teóricos, empíricos e de obras de autores que abordaram a promoção de leitura, conseguimos elaborar uma estratégia para promover o gosto pela leitura aos usuários das bibliotecas públicas de Angola. Pretende-se melhorar o gosto pela leitura dos usuários e levá-los a aprofundar mais sobre a literatura angolana. A estratégia prevê acções que possam fortalecer a formação de usuários leitores e outros interessados e dessa forma transformarem-se em bons leitores. Como já foi elucidado anteriormente, as estratégias escolhidas par a elaboração do modelo a propor para a Biblioteca Nacional de Angola, são as de Elisa Cristina Delfini Corrêa (2014) narrativa transmídia como estratégia de incentivo à leitura e foi combinada com a estratégia de incentivo à leitura nas escolas estaduais do estado de minas gerais de Secretaria de Estado de Educação de Minas Gerais (2017).

\subsubsection{Narrativa transmídia como estratégia de incentivo à leitura}

O modelo da narrativa transmídia, considera que as bibliotecas que utilizam os sons e movimentos para a promoção da leitura, sempre obtêm maiores resultados, relativamente ao hábito de leitura dos seus usuários. Aqui, a 
Biblioteca é apresentada como um espaço de lazer cultural.

Para isso, Gosciola e Versuti (2012) citado por Corrêa (2014, p. 101), consideram que $a$,

Narrativa transmídia ainda está em construção, embora em fase conclusiva: Como conceito, a narrativa transmídia vem se definindo aos poucos e está bem próxima de sua conclusão. Mas os primeiros usos do termo são muito significativos (Gosciola, 2011). Aparece primeiramente como trans-media composition (Welsh, 1995, p.97) definido pelo compositor e instrumentista Stuart Saunders Smith, para a peça Return and Recall de 1976, como uma composição em que melodia, harmonia e ritmo diferentes de cada instrumento são novamente compostos por cada executor, que complementaria a obra em coerente harmonia e sincronia com os outros instrumentistas/ compositores da peça (Gosciola e Versuti, 2012 citados por Corrêa, 2014, p. 101).

O termo transmídia foi introduzido como objeto de estudos no campo da comunicação através da publicação de um livro em que o termo transmedia intertextuality indicava a criação de um sistema de entretenimento no qual crianças experimentavam "a ampliação narrativa de uma história ao assistir à série de desenhos na TV, brincar com os brinquedos e ao assistir a um filme no cinema das mesmas personagens" (Gosciola e Versuti, 2012 citados por Corrêa, 2014, pp. 101-104).

Portanto, o leitor utiliza o seu computador para interagir-se com o meio que o rodeia "sociedade". Após o contacto com a informação, o leitor fica faminto com a necessidade de procurar mais e mais informações para o seu consumo. $\mathrm{E}$ isto faz dele um consumidor com características diferentes dos de mais.

O leitor ao utilizar os recursos tecnológicos (computador),

(...) tornaram-se caçadores e coletores de informação, possuem prazer em rastrear as origens das personagens e pontos da trama e fazer conexões entre textos diferentes dentro da mesma franquia. (...) Todas as evidências sugerem que os computadores não anulam outros meios de comunicação, em vez disso, os proprietários de computador consomem, em média, significativamente mais televisão, filmes, CD's, e mídia relacionadas do que a população em geral. (Jenkins, 2003 Citado por Corrêa, 2014, pp. 101-102).

Verifica-se a solicitação da utilização de vários meios para tornar a actividade mais interativa e chamativa. É por isso que o mesmo autor sustenta que "cada meio faz o que faz de melhor para que a história possa ser introduzida num filme, expandida através de televisão, romances e quadrinhos, e seu mundo pode ser explorado e experimentado também através de jogo. Cada entrada da franquia precisa ser bastante auto-suficiente para permitir o consumo autônomo. Você não precisa ter visto o filme para desfrutar do jogo e viceversa". (idem). A leitura através da mídia sustenta uma profundidade de experiência que motiva mais consumo.

Veja-se por exemplo, como funciona este método caso pretendamos falar de jogo.

O jogo é transmitido na Televisão, na rádio e na internet; na Televisão, o jogo é transmitido ao vivo com narração do comentarista; na Rádio, são transmitidos os bastidores do jogo, como entrevista com 
torcedores, ex-jogadores, etc.; na Internet, a pessoa pode conferir todas as substituições, cartões, gols, ver replays, históricos de partidas de ambas as equipas. (Jenkins, 2003 Citado por Corrêa, 2014, p.105).

Podemos concluir que, os três elementos formam um sistema, pois, os meios, juntos, fortalecem uns aos outros e complementam a sua mensagem através do que se observou, ouviu ou leu.

\subsubsection{Estratégia de incentivo à leitura nas escolas estaduais do Estado de Minas Gerais}

Esta estratégia apresenta algumas ações que tem como finalidade a formação dos leitores e/ou estudantes, professores e investigadores. Segundo o documento, atividades desenvolvidas possuem caráter transversal, isto é, cumprem com todas as fases de ensino e aprendizagem dos mesmos, através da leitura.

A estratégia está estruturada da seguinte forma: contextualização da proposta, seu objetivo e a perspectiva; eixos norteadores do trabalho, sendo eles: apropriação da biblioteca es-colar e agente de incentivo à leitura, fatores importantes para a organicidade das propostas; a relação desses eixos com os sujeitos articuladores, seus princípios e possíveis práticas em contexto educativo e própria proposta da constituição do Clube de Leitura.

Escolheu-se como ferramenta para a construção da estratégia para o fomento do gosto pela leitura nas bibliotecas públicas de Angola, o Clube de Leitura, que é uma das estratégias de grande potencial para o incentivo à leitura. Motiva o hábito de ler, assim como promove reflexões para além do lido e do compreendido, como, por exemplo, debate sobre temas cotidianos (Secretaria de Estado de Educação de Minas Gerais, 2017).

\subsection{Elaborando a estratégia metodológica (combinada)}

A estratégia metodológica criada é fruto da combinação das estratégias anteriormente apresentadas, possui sete (7) acções fundamentais.

\subsubsection{Objectivo da Estratégia Criada}

Incentivar o gosto pela leitura dos usuários e público em geral

\section{1a ACÇÃO: Clube do livro Impresso}

Objectivo: Fortalecer a formação de usuários leitores nas bibliotecas públicas.

Tarefa: Fazer sugestões de livros, criar grupos fechados e abertos de debates sobre os livros lidos.

Responsáveis. Responsáveis da área de promoção de leitura em colaboração 
com alguns professores.

Tempo: Mensalmente. $3 \mathrm{~h} / \mathrm{dia}$.

O clube do livro impresso é muito importante no processo de incentivo à leitura, sendo que dentro dele podem constituir-se diversas actividades que permitam fazer a reflexões sobre o que se leu através de debates dos livros lidos, de temas relacionadas ao quotidiano e encontros com escritores.

\section{2a ACÇÃO: Clube do livro digital}

Objectivo: Formar habilidades no uso da informação digital através de meios electrónicos.

Tarefa: Usar as redes sociais e portal de Leitura para fomentar a leitura.

Responsáveis: Direcção das bibliotecas públicas, responsáveis na área de promoção de leitura e os responsáveis da área de informática.

Tempo: Trimestral. 1h/dia.

Através do clube de livro digital, pode-se encorajar as pessoas (usuários) a fazerem uma leitura por prazer e não por imposição e bem como se pode propiciar fóruns on-line de leitura com adolescentes e discutirem os livros lidos, por forma a socializarem-se, principalmente os indivíduos tímidos. Por semana cada membro do grupo escolhe o que vai ser debatido na semana próxima como também podem se publicar alguns parágrafos relevantes do livro para que outras pessoas que não tiveram acesso ao livro impresso possam fazer a sua leitura naquele mesmo instante e assim manterem-se atualizados sobre $o$ assunto.

\section{3a ACÇÃO: Realização da Hora do conto}

Objectivo: Formar contos através de sua imaginação.

Tarefa: Escolher história, contar história e explicar a história.

Responsáveis: Funcionários da área de promoção de leitura.

Tempo: Semanalmente.

A hora do conto pode ser considerada como o tempo reservado para realizar actividades leitoras através do conto de histórias. Essas histórias, de preferência, deve ser curtas para desta forma despertar a criatividade do leitor, desenvolvendo capacidades imaginárias que lhe levará a viajar dentro da história e buscando sua própria conclusão. A hora do conto é uma valorização da literatura de textos, onde a criança começa desde cedo a conviver com os livros, sabendo que os mesmos proporcionam alegria, fantasia e muitas descobertas.

\section{4a ACÇÃO: Promoção da Criatividade}

Objectivo: Tornar o leitor em um ser criativo.

Tarefa: Orientar o leitor na sua escolha e propor alguns livros. 
Responsáveis: Bibliotecários e mediadores.

Tempo: Mensalmente.

Com está acção pretende-se que o usuário através de livros já lido ou de histórias contadas e vivenciadas use a sua criatividade para escrever o seu parecer acerca de tudo que ouviu e vivenciou durante a sua caminhada para isso o leitor tem que ter:

1. Uma mente curiosa para pensar sobre o que lê;

2. Ouvidos para sentir as histórias lidas por ele ou contadas por outros;

3. Mãos para segurar o livro com carinho;

4. Boca para ler com vontade.

A promoção da criatividade, permite que o leitor/usuário construa o seu próprio conhecimento através do que leu, ouviu e assistiu.

\section{5a ACÇÃO: Confecção do Baú do livro}

Objectivo: Incentivar a troca de obras entre os usuários e a biblioteca.

Tarefas: Colocar um baú com diferentes obras.

Responsáveis: Direcção das bibliotecas e os responsáveis na área de leitura.

Tempo: Semanalmente.

Nesta actividade o objectivo primordial é estabelecer um intercâmbio entre os usuários e a Biblioteca, principalmente em Bibliotecas Escolares (BE). Para isso, os professores ou os bibliotecários colocam um baú ou, na falta de um baú, pode-se colocar uma mala com diferentes obras da literatura nacional e internacional. Incentivar os alunos ou usuários a trazerem livros e colarem dentro do baú ou mala.

\section{6ª ACÇÃO: Leitura Transmídia}

Objectivo: tornar o ouvinte em caçador de partes da história.

Tarefas: O leitor deve participar na construção da história, escolher um filme e produzir um vídeo a partir de imagens dos personagens do filme escolhido de acordo com as novas versões da história.

Responsáveis: Funcionários da área de leitura e todos os envolvidos. Tempo: Mensalmente.

Com ajuda dos meios de comunicação de massa como a rádio e a televisão, escolhe- se, uma série ou filme visto por todos os participantes da actividade e cada um vai dizer qual foi a sua compreensão do mesmo filme ou série. Consoante o entendimento que cada um teve cria-se uma nova série e ser apresentado em forma de uma peça teatral por eles mesmo. Se o filme ou a série ainda estiver a decorrer, pede-se que cada um crie um final do filme. 
Objectivo: Divulgar todas as actividades voltadas a leitura

Tarefas: Criar panfletos a ilustrar as actividades e colocar na entrada da instituição de forma a chamar a tensão das pessoas que estiverem a passar, criar cartazes para serem distribuídos por todos os usuários, público em geral, com informações do local e a data das actividades e fixar. A biblioteca pode fazer parceria com alguns meios de comunicação como a rádio ou a televisão para emitir anúncios a fim de atrair o maior número possível de participantes.

Responsáveis: Responsáveis da promoção de leitura em colaboração com o responsável pela divulgação das actividades.

Tempo: Dois meses antes de cada actividade.

\section{CONCLUSÕES}

A Biblioteca Nacional de Angola, constitui um símbolo da cultura angolana, no que toca a promoção da leitura e na formação de leitores críticos e autodidatas. Por isso, pensamos que a estratégia apresentada contribuirá no fomento da promoção do hábito pela leitiura.

É importante que a biblioteca pública se tenha em conta durante a formação de leitores, o planeamento cuidadoso das actividades, desde a selecção do espaço, o ambiente e a introdução da estratégia. Para que a estratégia fosse considerada adequado e eficaz fez-se uma avaliação com ajuda de especialistas, foram solicitados cinco (5) especialistas da área em estudo.

Pode dizer-se que, a proposta da estratégia poderá ajudar as bibliotecas públicas a melhorarem as suas actividades, principalmente aquelas voltadas à leitura e, seguindo esta via, poderá transformar a mesma em um lugar mais atractivo e acolhedor. Ao longo de todo processo cumpriu-se com todos objectivos traçados e através da realização deste estudo, foi possível tomar consciência da importância da integração da leitura nas pessoas desde a infância, tendo culminado com a elaboração de uma estratégia com sete acções (7).

É necessário que as bibliotecas públicas estejam preparadas para desenvolver um conjunto de actividades que possibilite e ou ajude os usuários cultivarem o gosto pela leitura. Através dos resultados obtidos no campo de acção elaborou-se uma estratégia constituída por acções que visam a fortalecer - gosto pela leitura dos usuários nas bibliotecas públicas. A estratégia pode efectivamente estimular a formação de leitores, através de diversas actividades que cada uma das acções pretendem desenvolver.

\section{REFERÊNCIAS}

Arana, A. R. A., Albano, G. G. \& Ferreira, T. da S. (2013). Estratégias da leitura na Escola. Colloquium Humanarum, 10(Especial), 1402-1410. DOI: 10.5747/ch.2013.v10.nesp.000600 
Basílio, R.J.L. (2016). Uma Biblioteca Digital de Azulejaria Cerâmica. Recuperado em https://repositorio.ul.pt/handle/10451/26348.

Bernardino, M. C. R. \& Suaiden, E. J. (2011). O papel social da biblioteca pública na interação entre informação e conhecimento no contexto da ciência da informação. Perspectivas em Ciência da Informação, 16(4), 29-41.

Borges, A.T. (2016). Um estudo de leitura. Investigações em ensino de ciências, 2(3), 207-266. Recuperado em https://www.if.ufrgs.br/cref/ojs/index. php/ienci/article/view/628.

Carmo, H. \& Ferreira. M. M. (2008). Técnicas de recolha de dados em investigação qualitativa. Recuperado em http://repositorio.ipsantarem. pt/bitstream/.

Carvalho, M.C. (2011). Biblioteca Pública: Directrizes de criação, implantação, funcionamento e manutenção. Recuperado em http://rabci.org/rabci/ node/401.

Carvalho, R. J., Nobre, A., Gauer, G. \& Salles, J. (2015). Construção da tarefa de leitura de palavras e pseudo palavras (TLPP) e desempenho de leitores proficientes. Temas em Psicologia, 23(2), 413-429. Recuperado em http://www.redalyc.org/html/5137/513751491012/.

Cavalcante, M. (2006). Alfabetização: Todos podem aprender. Recuperado em https://pt.slideshare.net/cefaprodematupa/metodologia-ealfabetizao.

Cichoski, R. M. G. (1999). Dinamização da biblioteca: uma ação pedagógica. In: Vianna, M. M., Campello, B. S., Moura, V. H. V. (Ed.). Em Biblioteca escolar: espaço de ação pedagógica (pp. 151-165). Belo Horizonte, Brasil : Escola de Biblioteconomia da UFMG.

Corrêa, E.C. D. (2014). A narrativa transmídia como estratégia de incentivo à leitura. Texto Digital, 10(2), 98-113. Recuperado em http://dx.doi. org/10.5007/1807-9288.2014v10n2p98 
Decreto Presidencial n. ${ }^{\circ}$ 270/11 de 26 de Outubro. (2011). [Rede Nacional de Bibliotecas Públicas de Angola]. Publicada em Diario da República. I série. N. 207.

Decreto-lei n49.448 de 27 de Desembro. (1969). [Criação da Biblioteca Nacional]. Publicado em Boletim Oficial de Angola. I série. N. ${ }^{\circ} 301$.

Feitosa, L.T. (1998). O poço da draga: a favela e a biblioteca. São Paulo, Brasil: Annablume, Fortaleza, Secretaria da Cultura e Desportos.

Freitas, M. A. \& Silva. V.B. (2014). Bibliotecas Pública Brasileiras: Panorama e perspectivas. Rev. digit. bibliotecon. cienc. Inf, 12(1), 123-146. Recuperado em https://periodicos.sbu.unicamp.br/ojs/index.php/ rdbci/article/view/1621.

Gomes, D. (2016). A animação socio cultural na promoção de leitura. Recuperado em: https://repositorio.utad.pt/bitstream.

Hillesheim, A.I. de Andrade \& Fachin, G.R.B. (2003). Biblioteca Escolar e a Leitura. Revista ACB., 8(1). Recuperado em https://revista.acbsc.org.br/ racb/article/view/404/507

Kleiman, A. (1997). Aspectos Cognitivos da Leitura. Campinas, São Paulo, Brasil: Pontes.

Manifesto da IFLA UNESCO para Bibliotecas Públicas. (2000). Bibliotecas Públicas Princípios e Diretrizes.

Manifesto da IFLA UNESCO para Bibliotecas Públicas.(1994). Recuperado em: https://www.ifla.org/files/assets/public-libraries/publications/PLmanifesto/pl-manifesto-ptbrasil.pdf

Milanesi, L. (1986). Ordenar para desordenar. São Paulo: Brasiliense. 
Pereira, A. C. (2015). Cineclubes: uma forma alternativa de ver cinema em Portugal. Imagofagia. Recuperado em: http://asaeca.org/imagofagia/ index.php/imagofagia/article/view/43.

Santos, J.M. (2014). A cultura da informação nas bibliotecas públicas brasileiras. Revista Brasileira de Biblioteconomia e Documentação, 10(1), 54-67.

Secretaria de Estado de Educação de Minas Gerais. (2017). Estratégias de incentivo à leitura nas escolas estaduais do Estado de Minas Gerais. Minas Gerais, Brasil: ACS/SEE. Recuperado em http://www2. educacao.mg.gov.br/images/documentos/ESTRATE\%CC\%81GIAS INCENTIVO A LEITURA.pdf

Silva, E. T. (2011). Leitura e realidade brasileira. Porto alegre, Brasil: Edições Leitura Crítica.

Silva, J. A. da. (2011). Discutindo sobre leitura. Letras Escreve. Revista de Estudos Linguísticos, 1(1). Recuperado em https://periodicos.unifap.br/ index.php/letras/article/viewFile/326/n1jose.pdf

Silva, J.R, Almeida.C.D \& Guindani.J.F. (2009). Pesquisa documental. Recuperado em: http://www.praticadapesquisa.com.br/.

Silva, J.R. da. (2015). O uso de estratégias de leitura e compreensão como prática social (Tese de Mestrado). Universidade do Estado de Bahia, Brasil. Recuperado em http://www.saberaberto.uneb.br/jspui/ handle/20.500.11896/468

Souza, J. D. de. ( 2009). A biblioteca e o bibliotecário escolar no processo de incentivo à leitura: uma pesquisa bibliográfica (Tese de Licenciatura). Universidade Federal de Santa Catarina, Florianópolis, Brasil. Recuperado em https://repositorio.ufsc.br/handle/123456789/119542 


\section{e-Ciencias de la Información}

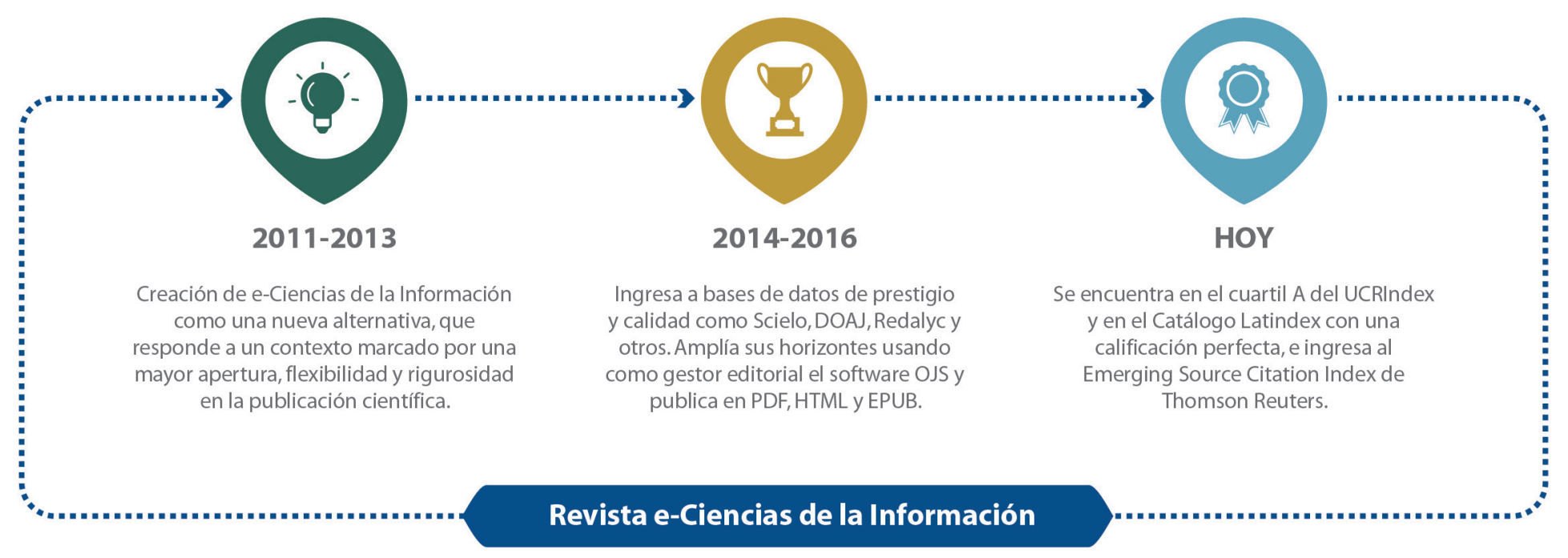

¿Dónde se encuentra idexada e-Ciencias de la Información?

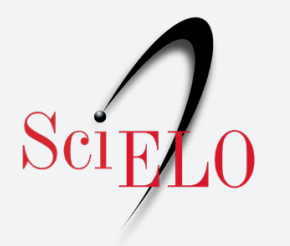

\section{latindex 12 clarivate Analytics}

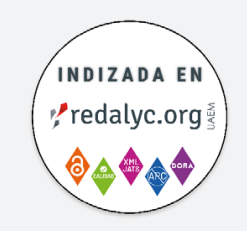

Para más información ingrese a nuestra lista completa de indexadores

¿Desea publicar su trabajo?

Ingrese aquí

O escríbanos a la siguiente dirección revista.ebci@ucr.ac.cr 